\title{
Marias que contam histórias: a escrita da vida e as marcas de uma escrita negra em três autoras brasileiras ${ }^{1}$
}

\author{
Marías que cuentan historias: la escritura de la vida y las marcas de una \\ escritura negra en tres autoras brasileñas
}

\author{
Marias who tell stories: the writing of life and the marks of a black writing \\ in three Brazilian authors
}

\section{Maria de Nazaré Barreto Trindade ${ }^{2}$}

\begin{abstract}
Resumo
Este artigo pretende fazer uma discussão sobre a produção literária de três autoras negras, diaspóricas e que até bem pouco tempo estavam ausentes das rodas de conversas, das discussões acadêmicas e das referências de autores considerados como os grandes críticos da literatura brasileira, entre eles Alfredo Bosi e Antonio Candido. Três mulheres, mil histórias - mil formas de se contar: a escrita de Maria Firmina, Carolina de Jesus e Conceição Evaristo compõem a busca de se construir outro cânone literário ou pelo menos de assegurar o lugar de fala e de escrita de escritores (as) negros (as) postos no completo anonimato. Alguém incomodada com a forma estrutural como a literatura organiza os seus lugares, penso que é necessário se construir outro, um que traga das margens, os inominados, os ausentes, aqueles que tendo nome foram apagados, aqueles que assim mesmo teimaram em escrever no tecido de dias e noites sua história, suas angústias e esperanças, suas palavras, suas coisas, seus diários, seus dizeres, suas dores e lamentos, sua vida, em papéis catados no lixo, em noites mal dormidas por dificuldades de uma vida inteira. Enfim, a tarefa central é estudar e produzir conhecimento sobre a literatura de um grupo subalternizado pela história de escravização, pelas diásporas. É uma escolha ideológica também trazer para a superfície do papel a escrita de mulheres que ousaram falar a partir do seu espaço de pertencimento, a partir das suas lutas que deixam de ser individuais para se tornarem lutas de um povo, de um coletivo social.
\end{abstract}

Palavras-Chave: Diáspora; Literatura negra; Mulheres; Subalternos; Interseccionalidade

\section{Resumen}

Este artículo pretende hacer una discusión sobre la producción literaria de tres autoras negras, diásporicas y que hasta muy poco tiempo estaban ausentes de las ruedas de conversaciones, de las discusiones académicas, y de las referencias de autores considerados como los grandes críticos de la literatura brasileña, entre ellos Alfredo Bosi y Antonio Candido. Tres mujeres, mil historias-mil formas de contar: la escritura de María Firina, Carolina de Jesús y Concepción Evaristo. Compone la búsqueda de construir otro canon literario o al menos de asegurar el lugar de habla y de escritura de escritores negros puestos en el completo anonimato. Alguien incomodada con la forma estructural como la literatura organiza sus lugares, pienso que es necesario construir otro, uno que traiga de las márgenes, los inominados, los ausentes, aquellos que teniendo nombre fueron borrados, aquellos que así mismo teimaron en escribir en el tejido de días y noches su historia, sus angustias y esperanzas, sus palabras, sus cosas, sus diarios, sus palabras, sus dolores y lamentos, su vida, en papeles a la basura, en noches mal dormidas por dificultades de una vida entera. En fin, la tarea central es estudiar y producir conocimiento sobre la literatura de un grupo subalternizado por la historia de esclavización, por las diásporas. Es una elección ideológica también que traer a la superficie del papel la escritura de mujeres que se atrevieron a hablar de su espacio de pertenencia, a partir de sus luchas que dejan de ser individuales para convertirse en luchas de un pueblo, de un colectivo social.

\footnotetext{
${ }^{1}$ Artigo apresentado no Simpósio Temático (ST 12 - Relações Étnico-Raciais na América Latina: debates interseccionais na diáspora) durante o II Seminário Latino-Americano de Estudos em Cultura - SEMLACult em Foz do Iguaçu/PR, Brasil, 2018.

${ }^{2}$ Mestra em Estudos Literários pela UFPA; Doutoranda em Antropologia Social- PPGA/UFPA; Belém, Pará, Brasil; CV: e-mail de contato: moaraufpa@ hotmail.com.
} 
Palabras- Clave: Literatura negra, Mujeres, Diáspora, Subalternos;

\begin{abstract}
This paper intends to make a discussion about the literary production of three black diasporic authors who until very recently were absent from the wheels of conversation, academic discussions, and the references of authors considered as the great critics of Brazilian literature, among them Alfredo Bosi and Antonio Candido. Three women, a thousand stories-a thousand ways to count: the writing of Maria Firmina, Carolina de Jesus and Conceição Evaristo. They compose the quest to construct another literary canon or at least to assure the place of speech and writing of black writers put in complete anonymity. Someone bothered with the structural form as literature organizes its places, I think it is necessary to build another, one that brings from the margins, the innominates, the absent ones, those that have names were erased, those that even stubborn in writing on the fabric of days and nights, his history, his anguish and his hopes, his words, his things, his diaries, his words, his pains and lamentations, his life, in papers heaped on the garbage, on nights that were badly asleep because of difficulties of a lifetime. Finally, the central task is to study and produce knowledge about the literature of a group subalternized by the history of enslavement by diasporas. It is an ideological choice to also bring to the surface of the paper the writing of women who have dared to speak from their space of belonging, from their struggles that are no longer individual to become struggles of a people, a social collective.
\end{abstract}

Keywords: Black Literature, Women, Diaspora, Subalterns.

\title{
1. INTRODUÇÃO- AS MULHERES NA LITERATURA BRASILEIRA
}

Existe de fato uma voz feminina negra na Literatura? Como isso é evidenciado na sociedade Brasileira? No decurso da história só é possível falar da literatura escrita e publicada por mulheres, se traçarmos um perfil da constituição da sociedade brasileira enquanto sociedade e relacionar essa escrita com as relações de poder historicamente estabelecidas no contexto do Estado.

Este artigo pretende ser o início de uma caminhada. São reflexões que constituem parte do que se vem levantando acerca das referências para a tese de doutoramento, cuja temática discorre sobre a presença do negro na literatura amazônica. Assim numa perspectiva antropológica pretende-se problematizar as relações de poder que implicam em subalternidade e silenciamento de atores sociais, essencialmente as mulheres negras. Neste intuito, encaramos a literatura também como campo de poder, espaço construído histórica e socialmente, onde as publicações e o acesso às obras foram controlados por homens, brancos e de classes sociais privilegiadas. Pretende-se traçar então algumas linhas e fortalecer o encontro diacrônico de três autoras: Maria Firmina dos Reis, Carolina Maria de Jesus e Conceição Evaristo.

A Literatura brasileira é um campo de poder pouco disputado pelas classes desfavorecidas e menos ainda pelas mulheres, que historicamente tiveram seus nomes ocultados, subtraídos dos compêndios. Livro publicado por Regina Dalcastagné aponta que após o estudo de 258 romances brasileiros publicados pelas principais editoras do país 
Companhia das Letras, Record e Rocco, com o recorte de 165 escritores "72,7\% são homens e o mais gritante, destes, $93,9 \%$ dos autores e autoras estudados são brancos" (DALCASTAGNÉ, 2012, p.89).

Não obstante esse quadro de pouca participação da mulher nos espaços de publicação, a autora aponta certa tendência de crescimento: elas estão sendo mais publicadas por grandes editoras do que antes. A autora, depois de estudar os romances publicados entre $1990 \mathrm{e}$ 2004, fez o mesmo com romances da época da ditadura, de 1965 a 1979. Das décadas de 1960 e 1970 para as décadas de 1990 e 2000, a proporção de autoras cresceu de 17,4\% para 27,3\%, uma possível conquista do feminismo que floresceu nesse período. Já a presença de personagens femininos decaiu de 40,7\% para $37,8 \%$. No que diz respeito à cor, a proporção de autores brancos cresceu de $93 \%$ para $93,9 \%$.

E quando se trata de autores e personagens negros? Em seu estudo sobre a representação do negro nos romances aponta ainda uma participação insignificante de 7,9\% contra 79,8\% de brancos (DALCASTAGNÉ, 2012). Resta-nos interpretar esses dados com base na compreensão de que a construção da nacionalidade brasileira tem sido marcada pela incontestável tentativa de excluir vozes do cenário nacional e de pôr na subalternidade todos aqueles que se proferem e se autoidentificam como negra (o).

Essa ausência se quisermos usar a referência de Boaventura de Sousa - Sociologia dos ausentes, ou mais contundente, esse silenciamento imposto pelas condições societárias brasileiras de cortes patriarcal, racial, étnico e sexista, que desde seu nascedouro colonial impôs ao feminino tarefas unicamente procriadoras e mantenedoras da felicidade do lar. A condição feminina de subalternidade é representada em diversos romances principalmente do século XIX. É claro que a resistência sempre existiu e se traduziu em lutas por sufrágio, por acesso à educação, marca inclusive da luta de Maria Firmina que ainda em meados do XIX viria a ser a primeira professora nomeada em 1847 para a Cadeira de Instrução Primária, em Guimarães, Província do Maranhão.

Tornou-se ultrajante observar a forma vertical, branca e sexista como a literatura organiza o seu cânone, os seus pares. Esse incômodo e a entrada no curso de antropologia levaram-me a pensar como tecer nas malhas de uma sociedade marcadamente desigual outra história literária que traga das margens os inominados, os ausentes, aqueles que tendo nome foram apagados, aqueles que assim mesmo teimaram em escrever no tecido de dias e noites 
suas histórias, suas angústias e esperanças, suas palavras, suas lutas, seus diários, seus dizeres, suas dores e lamentos, sua vida, enfim, talvez seja essa a grande tarefa.

Neste sentido, esse diálogo inicia-se com uma questão-reflexão: Estuda-se um grupo social? De certo modo, sim. Estuda-se uma literatura diaspórica, a produção literária de um grupo subalternizado pela história da escravização, pelas diásporas. E isso está muito claro na vida dessas três mulheres: Maria Firmina dos Reis, Carolina Maria de Jesus e Maria da Conceição Evaristo de Brito, três Marias, três histórias de vida e re(e)xistência. Quantos outros nomes foram subtraídos à História e à Literatura?

Numa pesquisa inicial constatou-se a incômoda ausência de vozes femininas na crítica literária de grandes estudiosos da literatura como, por exemplo, Alfredo Bosi, Antonio Candido, José Veríssimo, Nelson Werneck Sodré, José Aderaldo Castelo, José Guilherme Merquior, Afrânio Coutinho. Em Literatura e sociedade, Antonio Candido se remete ao feminino tão somente como público consumidor de uma literatura produzida: "Poucas literaturas terão sofrido, tanto quanto a nossa, em seus melhores níveis, esta influência caseira e dengosa, que leva o escritor a prefigurar um público feminino e a ele se ajustar" (CANDIDO, 2006, p. 88).

Não obstante esse papel de leitoras atribuído às mulheres, muitas delas foram além e se atreveram a esboçar suas escritas e a expô-las ao mundo. É bem o que diz Maria Firmina no prólogo do seu livro: "Mesquinho e humilde livro é este que vos apresento, leitor. Sei que passará entre o indiferentismo glacial de uns e o riso mofador de outros, e ainda assim o dou a lume" (REIS, 2017, p. 25).

\section{PODE A MULHER NEGRA FALAR? A CRÍTICA LITERÁRIA BRASILEIRA}

O título faz remissão ao livro de Spivak "Pode o subalterno falar?" E traduz uma inquietação em torno de como as vozes femininas, autorais, os temas, as perspectivas (visão de mundo)- a linguagem - a seleção de palavras-metáforas, a escolha de signos, como por exemplo a politica perpassam as obras de três autoras da literatura brasileira que em suas escrituras respondem e resistem a subalternidade. São literaturas que precisam ser lidas, avaliadas na sua força literária, enfim reconhecidas pelo grande público.

A escritora indiana Gayatri Spivak afirma nesse texto, publicado em 2010, pela editora da UFMG, que "se, no contexto da produção colonial, o sujeito subalterno não tem história e não pode falar, o sujeito subalterno feminino está ainda mais profundamente na 
obscuridade". Ao refletir sobre a história das mulheres indianas e da imolação das viúvas, Spivak aborda o lugar intrincado e inquietante ocupado pelas mulheres no contexto póscolonial. E mais, ao relatar a história de uma jovem indiana que não pode se autorrepresentar e, logo, não pode "falar" fora do contexto patriarcal e pós-colonial, Spivak exemplifica seu argumento de que o subalterno, nesse caso especial, a mulher como subalterna não pode falar e quando tenta fazê-lo não encontra os meios para se fazer ouvir”.

Heloísa Buarque de Hollanda afirma que, entre meados do século XIX e o primeiro decênio do século XX, houve um crescimento quantitativo da participação da mulher na literatura, aumento atribuído ao surgimento da imprensa, que possibilitou a criação de várias publicações dirigidas e editadas por mulheres. Nessa época cresciam os movimentos feministas e as campanhas republicanas de educação da mulher para a promoção de uma nação brasileira educada, saudável, branca e moderna.

Spivak faz um apelo a mulher intelectual - diz que a elas caberá a tarefa de criar espaços e condições de autorrepresentação e de questionar os limites representacionais , bem como seu próprio lugar de enunciação e sua cumplicidade no trabalho intelectual. Na direção de mudar esse cenário de tentativa de silenciar as vozes femininas alguns trabalhos estão vindo a lume. E o caso do trabalho coordenado pela professora pesquisadora Zahidé Lupinacci Muzart “Escritoras brasileiras do século XIX” publicado em 1999. Pelas mãos de sessenta e oito mulheres envolvidas no projeto um conjunto de cinquenta e uma escritoras brasileiras do século XIX. A prefaciadora fala da obra: mulheres amarrando as pontas de dois séculos, integrando norte, sul, leste, oeste, as Américas. E explica:

O livro é centrado nas escritoras, no fato de serem brasileiras, e em um tempo específico, porque significativo. Comecemos pelas brasileiras e por sua relação com o conceito norteador do século XIX. O conceito de nação está intrinsecamente ligado à escritura. Até porque não existe, a priori, uma definição de nação. Citemos alguns clássicos e o que dizem: "Não há um meio 'científico' de estabelecer o que todas as nações têm em comum." Nação é "qualquer corpo de pessoas suficientemente grande cujos membros consideram-se como membros de uma nação". Ou "o nacionalismo não é o despertar das nações para a autoconsciência: ele inventa nações onde elas não existem”.

A organizadora opta pelo conceito de nação enquanto escritura, o que vem ao encontro da formulação teórica de Hommi Bhaba:

Preferimos ficar com a concepção de que nação é escritura; o conceito alimenta-se de textos. Na base da formação da consciência nacional está o texto impresso; foi através dele que ela pôde existir. Logo, nada pode ser ignorado. Neste ponto em que chegamos, para reforçar a idéia de uma nova leitura da história literária do século XIX, descobrimos que o século XX passou sem termos solucionado a impossibilidade de se entender o século XIX, o centramento no nacionalismo e o 
processo de formação de uma história da literatura brasileira - mais exatamente, da cultura brasileira, ou de uma periodização delimitada por cânones indiscutíveis.

A pesquisadora Zahidé Muzart define seu trabalho e de sua equipe de pesquisadoras, como uma faina de 'revolver escombros e garimpar entulhos', que só pode ser levada a cabo 'com paciência e boa dose de paixão'. Nesta garimpagem o tempo é fator primordial, o que permite um repensar não apenas da literatura e do seu cânone, mas da própria história da nação brasileira.

Outro trabalho importante e orientado por essa concepção foi a produção do Dossiê mulheres negras, uma parceria da Secretaria de Políticas para as Mulheres da Presidência da República (SPM/PR), do Ipea, e da Secretaria de Políticas de Promoção da Igualdade Racial da Presidência da República (SEPPIR/PR) com a ONU Mulheres, no âmbito do projeto Retrato das desigualdades de gênero e raça, cuja quarta edição foi publicada em 2011. (dossiê mulheres negras). Este dossiê traz entre outros temas as questões em torno da relação entre gêneros. Em termos de análise de gênero conclui que:

a posse de bens tem repercussões sobre a evolução da chefia feminina nos domicílios e sobre o uso do tempo das mulheres, ainda principais encarregadas dos trabalhos domésticos e do cuidado com a casa. No que concerne à marginalização vinculada ao gênero, o estudo da evolução do acesso a bens na perspectiva comparada entre mulheres e homens permite localizar o processo de manutenção ou de superação de tendências de hierarquia entre os gêneros, que se revelam também nas dificuldades de acesso a bens pelas populações negras, especialmente pelas mulheres negras (2011, p. 82)

Segundo o dossiê "as disparidades de acesso a bens e a exclusão digital refletem as desigualdades sociais que dificultam a inserção da população negra e sua participação como cidadã na sociedade brasileira contemporânea" (p.82). Nesta perspectiva cabe dizer que a análise de questões relacionadas a gênero, raça e classe são fundamentais para entender o processo de ausência de negras e negros dos espaços literários, acadêmicos e de poder. Uma realidade que vem aos poucos se modificando, mas pela resistência e rebeldia de corpos negros que se impõem na sociedade brasileira.

A história da construção do Brasil enquanto nação independente envolve os diferentes discursos e representações que se construíram sobre os povos que aqui habitavam e sobre aqueles que vieram escravizados das nações africanas e, posteriormente, as representações sobre os processos de aproximação e miscigenação desses povos. Os estigmas e estereótipos construídos ao longo de mais de três séculos de escravização e genocídio de nações africanas e que são de fato de difícil enfrentamento como bem denuncia Fanon:

Na América, há pretos postos à margem. Na América do Sul, açoitam-se nas ruas e metralham-se os grevistas pretos. Na África ocidental, o preto é um animal. E aqui, 
mesmo ao meu lado, um colega da Faculdade, originário da Argélia, diz-me: 'Até fazerem do árabe um homem como nós, nenhuma solução será viável’ (p.145).

Ideias arraigadas, plantadas e planteadas na origem da construção do Brasil enquanto nação independente. É sem dúvida um desafio pensar as questões sempre viscerais em torno da constituição de nossa identidade, e, ainda, aquelas que configuram o Brasil enquanto nação e narração (Hommi Bhaba). E nesse caldo identitário a frase "Minha negritude rompe a prostração opaca de sua justa paciência”, proferida pelo poeta Aimé Cesaire e retirada do livro "Cadernos de um regresso ao país natal” mobiliza nossa imaginação em torno de pensar as diferentes formas de resistência ao domínio colonial, experimentadas por autores que viveram de diferentes formas e em diferentes locais as agruras das diásporas. Nas últimas quatro décadas vem se modificando, parte pela ação política de pessoas que trazem a lume as discussões sobre as relações raciais, a luta contra o domínio colonial e contra o racismo.

No início do seu livro Cultura e Imperialismo, Eduard Said (2011) afirma que:

A invocação do passado constitui uma das estratégias mais comuns nas interpretações do presente. O que inspira tais apelos não é apenas a divergência quanto ao que ocorreu no passado e o que teria sido esse passado, mas também a incerteza se o passado é de fato passado, morto e enterrado, ou se persiste, mesmo que talvez sob outras formas. Esse problema alimenta discussões de toda espécie acerca de influências, responsabilidades e julgamentos, sobre realidades presentes e prioridades futuras (p.31).

As questões em torno da luta contra o racismo e o colonialismo mobilizadas por intelectuais das diásporas caribenha e africana ecoaram em terras brasileiras e influenciaram o pensamento de escritores e ativistas políticos de diferentes áreas do conhecimento. É assim que no Brasil, por ocasião do centenário da abolição foi relançado o documento "A abolição no parlamento: 65 anos de luta (1823-1888)“ que traz algumas referências históricas importantes sobre o processo de resistência e abolição dos negros no Brasil. Começo com este texto por ter claro que todas as informações e representações gestadas e emitidas pelo discurso oficial e não oficial sobre a negritude tem sua origem nesses documentos da oficialidade brasileira e em registros de viajantes que por estas paragens fizeram pouso.

O escritor Franz Fanon em Pele negra, máscaras brancas expõe de forma contundente e avassaladora a realidade do aprisionamento do ser humano em sua epiderme, em sua cor de pele, expresso em: “O mundo branco, o único sério, recusava-me toda a participação. De um homem exigiam uma conduta de homem. De mim, uma conduta de homem preto- ou pelo menos uma conduta de preto. Eu chamava o mundo e o mundo amputava-me do meu entusiasmo. Pediam-me que me confinasse, que me retraísse" (p.147). Uma fala que ecoa como um grito e é isso mesmo que Fanon deseja caminhar sobre as palavras, afinal a palavra 
é mistificadora, criadora de significados, cortante, "carne trepidante" como quis Césaire. E por isso mesmo criadora de representações que marcaram e marcam a história do negro no Brasil.

Segundo Morris (2010) o trabalho Can the subaltern Speak? de Spivak articula uma crítica a teóricos do pós-estruturalismo, nas figuras de Foucault e Deleuze, e estende suas provocações a todo o território dominado pelos teóricos pós-coloniais - de Edward Said e Homi Bhabha à Partha Chatterjee e Dipesh Chakrabarty ((MORRIS, 2010, p. 9). Assim o livro que pergunta se o subalterno pode falar é precursor dos estudos sobre subalternidade. E pauta o debate pós-colonial. A crítica pós-colonial buscou repensar, de forma radical, as identidades sociais e todo o conhecimento autorizado e de autoria do colonialismo e do ocidente. Para isso, partiu da premissa que nem o nacionalismo, nem o marxismo, teriam conseguido se "libertar" de discursos eurocêntricos (PRAKASH, 1994, p. 1475).

Assim a discussão sobre a presença negra na literatura vem no bojo das discussões sobre subalternidade, feminismo negro, empoderamento feminino. Pensar a literatura produzida por três mulheres negras é estar no campo do conflito, que se estabelece nas formas de representação das personagens negras nos diferentes aportes literários e na ausência imposta de autores negros nos compêndios, essencialmente as mulheres. Nesta perspectiva as categorias da subalternidade e interseccionalidade constituem instrumentais importantes para analisar também a presença literária de mulheres na historiografia da área.

Estamos numa sociedade marcada por relações assimétricas e essas relações são evidenciadas de várias formas - dominação sexual, racial, classicista e essas relações são estruturadas a partir de determinadas ideias que se interconectam. É nesta perspectiva que a discussão metodológica a partir da interseccionalidade como categoria teórica auxilia na reflexão e nação sobre as problemáticas em torno dessas questões. O termo foi cunhado por Kimberlé Williams Crenshaw que "define a interseccionalidade como formas de capturar as consequências da interação entre duas ou mais formas de subordinação: sexismo, racismo, patriarcalismo".

\section{AS MARIAS QUE CONTAM HISTÓRIAS}

"A noite não adormece nos olhos das mulheres, a lua fêmea, semelhante nossa, em vigília atenta vigia a nossa memória. (...) donde Ainás, Nzingas, Ngambeles e outras meninas-luas afastam delas e de nós, os nossos cálices de lagrimas". Esse trecho de um 
poema de Conceição Evaristo (2017) mostra, poeticamente, como a memória é de fundamental importância nas literaturas femininas, e como essa memória aparece nas obras dessas três autoras que apresento a partir de agora.

São três grandes autoras da literatura brasileira. Elas são memórias-viva e inquietantes de um tempo, um tempo de luta e rebeldia. Desconhecidas do grande público, pouco estudadas e refletidas nos espaços formais de ensino, mas que se impuseram na cena Cultural de seus estados, tiveram dificuldades de toda ordem e apresentam um legado de escrita de vida e de resistência que deve ser considerado pelas gerações atuais e futuras desse país. É um encontro de mulheres que viveram em tempos históricos diferentes. Experenciaram as suas maneiras algumas agruras advindas da cor da pele e por habitarem uma nação que em seu processo sócio-histórico marginaliza e estigmatiza milhares de afrodescendentes.

$\mathrm{Na}$ cronologia do silêncio imposto, apresenta-se, inicialmente, Maria Firmina. Nasceu no bairro de São Pantaleão, na Ilha de São Luís, capital da província do Maranhão em 11 de outubro de 1825. Filha de pai negro e mãe branca. Era prima do escritor maranhense Francisco Sotero dos Reis. Seu romance é considerado uma crítica à escravidão. Revestido sob a influência ainda do romantismo, o romance traz alguns personagens- que demonstram algo de novo em relação aos personagens negros até então construídos.

O lançamento de "Úrsula" foi tímido, conhecido pela cidade de São Luiz por uma pequena nota no jornal "A Moderação" de 11 de agosto de $1860^{3}$, que expunha em suas últimas linhas "Úrsula - romance original brasileiro: a autoria feminina da Exma. Sra. D. Maria Firmina dos Reis, professora pública em Guimarães”. Considerada pioneira na crítica antiescravista da nossa literatura, Maria Firmina,

Negra, filha de mãe branca e pai negro, registrada sob o nome de um pai ilegítimo e nascida na Ilha de São Luís, no Maranhão, Maria Firmina dos Reis (1822 - 1917) fez de seu primeiro romance, Úrsula (1859), algo até então impensável: um instrumento de crítica à escravidão por meio da humanização de personagens escravizados (D’ ̃̂NGELO, 2017).

Em artigo publicado na ANPUH a professora Regia Agostinho da Silva da Universidade Federal do Maranhão afirma:

Maria Firmina dos Reis construiu uma voz dissonante na literatura do século XIX, principalmente por ser uma mulher escritora, em um período no qual a escrita pública era quase exclusivamente masculina, é voz dissonante também por ser mulata, autodidata e por escrever sobre os escravos em uma perspectiva completamente diferente do que foi colocado por outros literatos, como Bernardo

\footnotetext{
${ }^{3}$ Informação retirada da Revista CULT. Disponível em: https://revistacult.uol.com.br/home/centenario-mariafirmina-dos-reis/. Acesso em novembro de 2018.
} 
Guimarães, José de Alencar, onde os cativos eram vistos como vítimas passíveis da escravidão ou como elementos perniciosos no contato com as famílias brancas (SILVA, 2009, p.9).

O Escritor também maranhense Nascimento Moraes Filho publica em outubro de 1975, por ocasião do sesquicentenário do aniversário de nascimento da escritora, o livro Maria Firmina dos Reis - fragmentos de uma vida (Figura 1).

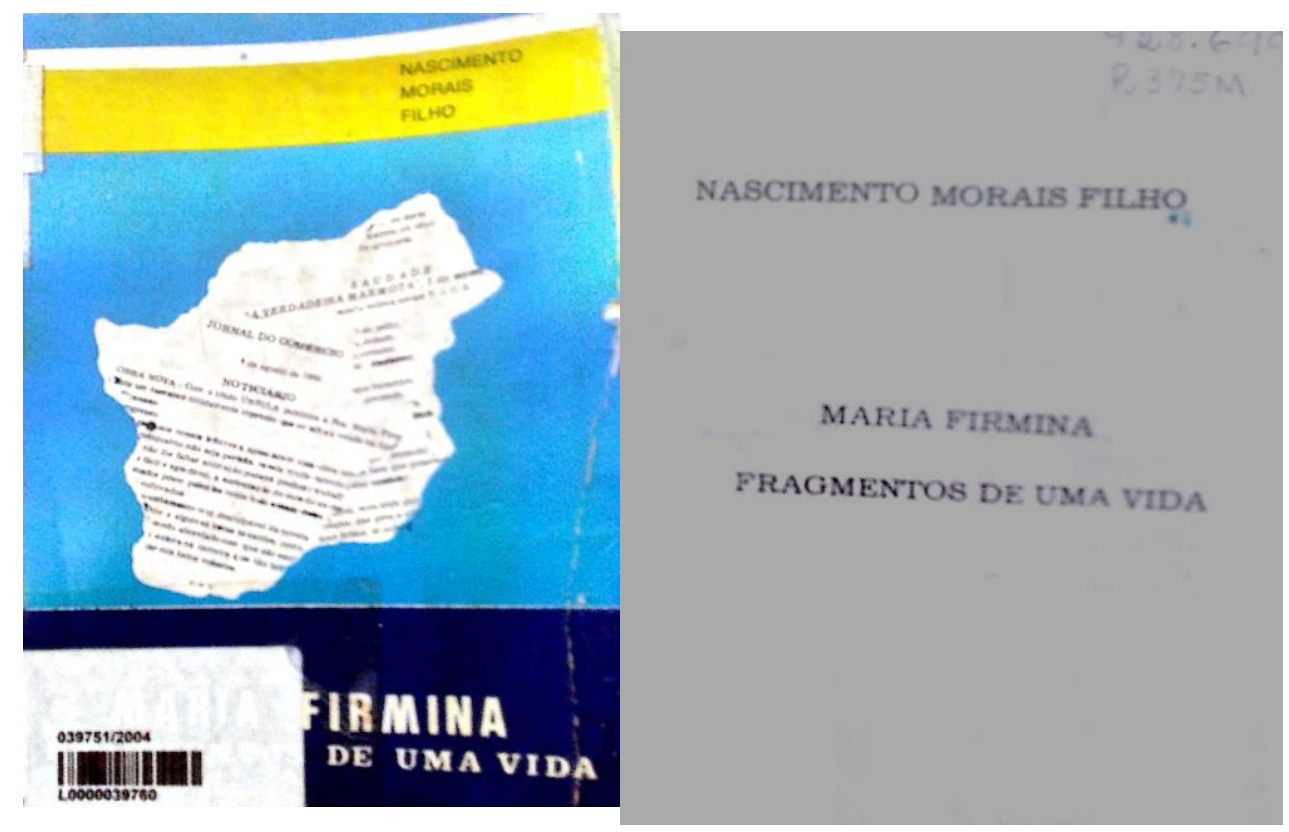

Figura 1- Capas de duas edições do livro sobre Firmina Fonte: Biblioteca Benedito Leite-foto da autora

A coletânea é composta de hinos, letras de músicas, contos, vários poemas e fragmentos de um diário, artigos de jornais. Referenciando Firmina o autor diz que ela e Dona Ana Jansen são duas individualidades femininas que deram outra dimensão para as mulheres maranhenses. A mulher maranhense deixou de ser apenas "Senhora prendada dos salões". Em suas pesquisas o autor "descobriu Firmina e assim a apresenta no livro:

Descobrimo-la, casualmente, em 1973, ao procurar nos bolorentos jornais do século XIX, na "Biblioteca Pública Benedito Leite", textos natalinos de autores maranhenses para nossa obra, "Esperando a Missa do Galo". Embora participasse ativamente da vida intelectual maranhense publicando livros ou colaborando quer em jornais e revistas literárias quer em antologias - "Parnaso Maranhense" - cujos nomes foram relacionados; em nota, sem exceção, por Silvio Romero, em sua História da Literatura Brasileira, registrada no cartório intelectual de Sacramento Blake - o "Dicionário Bibliográfico Brasileiro" - com surpreendentes informações, quase todas ratificadas por nossa pesquisa, Maria Firmina dos Reis, lida e aplaudida no seu tempo, foi como que por amnésia coletiva totalmente esquecida: o nome e a obra!... 
Seu conto "A escrava" publicado na Revista Maranhense de 1887 estabelece outro olhar sobre a escravização, escrito em plena campanha abolicionista, o que com certeza não agradou às elites maranhenses locais. Mendes (2006) aponta que há muito ainda a dizer sobre esta autora, mas essencialmente era alguém preocupada com a instrução pública:

Em seus poemas, encontram-se também epígrafes em francês. .Rastreando suas obras, podemos constatar marcas de George Gordon Byron, de Bernardin de Saint-Pierre, de Harriet B. Stowe, de Louis de Larmatine, de Willian Shakespeare, de Almeida Garret, entre outros. Esses dados são reveladores da leitora que ela foi. Nos excertos de seu Álbum ou, como se denomina na escritura literária, diário, cujo título é Resumo de minha vida apresenta seu posicionamento crítico acerca da educação patriarcal que provavelmente recebera (p. 27).

Carolina Maria de Jesus, mineira nascida em 14 de março de 1914 em Sacramento, interior de Minas Gerais, 26 anos após o decreto da propalada abolição da escravidão negra no país e do proclame da república, dois fatos que marcaram a história da sociedade brasileira àquele período. Carolina é filha de uma filha do ventre livre Maria Carolina de Jesus e de João Cândido Veloso, pai que ela não conheceu. E do qual temos conhecimento por meio de sua escrita, anos depois, no seu último trabalho, publicado postumamente em 1986, com o título Diário de Bitita: "Um dia ouvi de minha mãe que meu pai era de Araxá, e o seu nome era João Cândido Veloso. E o nome da minha avó era Joana Veloso. Que o meu pai tocava violão e não gostava de trabalhar. Que ele tinha só um terno de roupas" (JESUS, 1986, p. 6).

Em relação à escrita de Carolina é importante ressaltar que toda sua obra é muito significativa como retrato em preto e branco de uma situação social extremamente carente, conformada nas favelas em São Paulo. Foi em Canindé que viveu e escreveu grande parte de sua obra em papel usado catado no lixo. Nos 13 cadernos recolhidos pelo jornalista Audálio Dantas existe a pulsação frequente e forte de alguém que decidiu não desistir da vida, apesar de, em sua interpretação, a favela ser um lugar inóspito e de em alguns momentos ceder a um pensamento ruim, afinal, para ela, a favela era o infortúnio. Era onde "respirava o odor dos excrementos que mescla com o barro podre" (JESUS, 1960, p. 37).

Carolina tem uma opinião formada sobre a realidade que a cerca e disso constrói o estandarte de sua defesa contra os momentos difíceis na favela. E, ainda, veste uma "máscara social" que a individualiza diante dos outros, fortalece sua alteridade e a posiciona como a negra que lê, que toda noite enquanto os vizinhos se embebedam e brigam, senta-se e escreve os ocorridos naquele dia. Ela se diz:

O livro... me fascina. Eu fui criada no mundo. Sem orientação materna. Mas os livros guiou os meus pensamentos. Evitando os abismos que encontramos na 
vida. Bendita as horas que passei lendo. Cheguei a conclusão que é o pobre quem deve ler. Porque o livro, é a bussola que ha de orientar o homem no porvir (...)" (JESUS, 1986).

Carolina é uma mulher que em sua escrita expõe as marcas de uma sociedade que se constituía desde sua origem de forma extremamente desigual. Carolina faz uma leitura do seu mundo e traduz em palavras, com força de denúncia todo o drama, toda luta diária não apenas dela, mas de um coletivo, a favela, sujeito coletivo que emerge por esse período como signo de uma modernidade, possivelmente de uma modernidade líquida.

Chegamos aqui à última escritora, contemporânea, nascida na favela de Pendura Saia em Belo Horizonte, Minas Gerais, em 1946. Maria Conceição Evaristo de Brito é uma voz que hoje se posiciona na cena literária brasileira.Colaboradora do movimento negro em São Paulo, teve os seus primeiros escritos publicados nos Cadernos Negros, do grupo paulista Quilombhoje em 1989. Tem diversos contos publicados em obras coletivas e seis obras individuais, dentre elas, Becos da Memória e o romance Ponciá Vicêncio.

É só praticamente um século depois que Conceição Evaristo, assim como Carolina, numa atitude de resistência e de necessidade de dizer-se, de mostrar-se, de trazer à baila processos de discriminação social vivida pelas mulheres e mais ainda pelos negros diz numa entrevista que ao negro não interessa apenas uma cidadania lúdica, com Evaristo "Mais uma vez, foi reacesa a necessária discussão sobre racismo e a falta de representação da população negra na literatura brasileira". O que queremos, completa a autora são negros intelectuais, professores, pesquisadores, ocupando-se também da política, ou seja, uma cidadania intelectual.

A escritora mineira Conceição Evaristo disse que "para a mulher negra escrever e publicar é um ato duplamente político, primeiro porque é mulher, segundo porque negra, vivenciamos uma sociedade onde a cada dia são postos conflitos em torno do racismo e da discriminação social. Para ela:

A questão racial do Brasil não é para o negro resolver: é para o brasileiro. Talvez estejamos perdendo um pouco do nosso cinismo. Perdemos o medo de colocar o dedo na ferida." E arremata: "A nossa 'escrevivência' não pode ser lida como histórias para 'ninar os da casa grande' e sim para incomodá-los em seus sonos injustos.

Em Conceição há o desejo de contar, de usar a palavra como instrumento não para ferir, mas para inquietar, afinal durante tanto tempo as cantigas de negro ninaram o sonho dos algozes, agora é hora de incomodá-los em seus sonhos injustos(CE). Conceição problematiza 
o espaço de publicação: e escolhe também publicar, porque segundo ela " [...]se para as mulheres brancas escrever é um ato político, para as mulheres negras é mais ainda", dada até, mas ainda você acrescenta também essa perspectiva da publicação que é mais difícil do que para as mulheres brancas.

Como alguém que reflete sobre seu país, sobre as condições impostas a uma maioria negra que entra nas estatísticas de homicídios e feminicídios, Conceição Evaristo busca pensar de forma esperançosa e resistente nesse contexto de profundo e contundente ataque às liberdades e aos direitos historicamente conquistados, lembrando que a literatura deve trazer textos de enunciação que quebrem com os estereótipos e discriminações:

Tendo sido o corpo negro, durante séculos, violado em sua integridade física, interditado em seu espaço individual e social pelo sistema escravocrata do passado e, hoje ainda por políticas segregacionistas existentes em todos, senão em quase todos, os países em que a diáspora africana se acha presente, coube aos descendentes de africanos, espalhados pelo mundo, inventar formas de resistência. Vemos, pois, a literatura buscar modos de enunciação positivos na descrição desse corpo. A identidade vai ser afirmada em cantos de louvor e orgulho étnicos, chocando-se com o olhar negativo e com a estereotipia lançados ao mundo e às coisas negras.

\section{UM POUCO DA DISCUSSÃO(AÇÃO)}

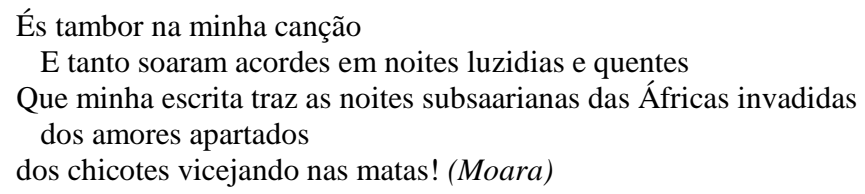

Inicialmente, existem nas autoras estudadas alguns aspectos identitários comuns, um deles é a ligação em maior ou menor grau com a violência física, simbólica e social da escravização de milhares de seres humanos que aqui aportaram. Em segundo lugar, as três produziram uma escrita da vida, como diz Conceição Evaristo, "escrevivência", expondo as agruras da vida de negros no Brasil, em três contextos diferentes apenas do ponto de vista das condições sociais e econômicas vigentes, diferentes, mas onde questões ideológicas e raciais são praticamente semelhantes, não fosse as diferentes formas de atingir o outro. Portanto, vislumbra-se uma escrita da resistência ao status quo posto.

Outro aspecto importante a ser assinalado é o da autoria, a coragem de lançar-se para o público. Lembrei-me de algo bem marcante quando li "Quarto de Despejo", de Carolina de Jesus. Em determinado momento do diário alguém pergunta a ela "negra fedida porque tu escreves"? E ela fica pensando e observa as outras mulheres e homens da favela e diz "Eu não danço, não canto, mas escrevo". Escrevia para sobreviver em meio a um cotidiano 
extremamente difícil, era catadora de lixo e registrava em papel amarrotado e amarelo a dureza e a alegria do seu cotidiano ${ }^{4}$.

Quando Carolina de Jesus, migrante de uma cidade chamada Sacramento em Minhas Gerais, chegou em Canindé - favela paulista às margens do Tieté buscou no cotidiano de sua lida de catadora de lixo, formas de registrar sua experiência humana, nos cadernos escreveu sua vida, suas relações sociais, suas dores, angústias, percepções do político , fome, enfim toda uma gama de temáticas relacionadas ao que anos mais tarde a também mineira Conceição Evaristo denominou de "escrevivência".

Carolina de Jesus escreve sua vida, se diz, é uma mulher que de alguma maneira quer contar sua história "Eu também sou rebotalho" (p.38). Rebotalho é aquilo que restou após a escolha do melhor, é o refugo, a escória da sociedade, a ralé. Essa representação de si mesma não a impediu de tentar ser mais, ser escritora. Nascida em meio à fome e precárias condições de vida, Carolina não se deixou apagar. Não permitiu que aquela realidade que vivenciava ficasse apenas na memória afetiva, no sentido de que guardamos certa memória de acontecimentos passados, mas tornou-se memória social, como bem aponta Halbwachs. A memória viva e imediata de um lugar: a favela de Canindé, às margens do rio Tietê.

Carolina, em seu Quarto de despejo amplia o horizonte de sua escrita, mostrando sua capacidade de reflexão sobre o momento vivido: "E assim no dia 13 de maio de 1958 eu lutava contra a escravatura atual- a fome!” (JESUS, p.32). Critica a política e aqueles que em época eleitoral vão a favela fazer promessas e quando eleitos "Mas na câmara dos deputados não criou um progeto para beneficiar o favelado. Não nos visitou mais (JESUS, p.33).

Meio século depois, Conceição Evaristo reflete sobre estas questões: ao negro são associadas às representações da sensualidade, da dança, da musicalidade, resta agora mostrar ao mundo que há uma literatura rica em elementos ficcionais e temáticas escritas por peles negras, e que são vozes que saem aos poucos da sombra de cânones estabelecidos pelas vozes dominantes até então. Em entrevista ano passado com a professora Conceição perguntei sobre sua percepção atual acerca da subalternidade e de como a literatura poderia contribuir para quebrar alguns grilhões simbólicos, outros nem tanto, que ainda nos acorrentam às representações muito negativas da negritude. Ela respondeu:

\footnotetext{
${ }^{4}$ No artigo “CAROLINA, A MULHER PELO AVESSO: UMA POÉTICA DO DESASSOSSEGO”, publicado nos anais do V CIELLA faço uma análise literária de Quarto de Despejo, evidenciando esse protagonismo na escrita de Carolina de Jesus.
} 
[...] inclusive se você fala em termos concretos em termos reais você vai ver que na pirâmide social as mulheres negras é que estão ainda na pirâmide social, os trabalhos menos valorizados socialmente ainda cabem a essa mulher negra. E a literatura,ela pode ajudar através da educação, eu acho que a literatura, acho não, a literatura pelo fato de lidar com as emoções, talvez o efeito que um texto literário possa fazer é muito maior do que um texto histórico, mas ele primeiramente ele vai tocar as emoções, por exemplo, se você ler Um defeito de cor de Ana Maria, quantas informações aquele livro traz e é uma ficção, se fosse um texto histórico poderia não produzir tanto efeito assim (Informação verbal).

Assim é uma escolha ideológica trazer para a superfície do papel a escrita de mulheres que ousaram falar a partir do seu espaço de pertencimento, a partir das suas lutas diárias, incansáveis, exigentes, e são lutas que deixam de ser individuais para se tornarem lutas de um povo, de um coletivo social. Escrever é uma arte e a escrita autoral é uma conquista. Para finalizar, entende-se que as relações de poder estabelecidas no Brasil são extremamente perniciosas a vozes que se posicionam, que criticam, que refletem, sejam elas oriundas de quaisquer área do conhecimento. A literatura tem um papel importante de trazer à luz essas vozes subalternizadas, de produzir conhecimento sobre esses escritores. Como afirma Dalcastagné:

[...] é preciso reconhecer que nosso olhar é construído, que nossa relação com o mundo é intermediada pela história, pela política, pelas estruturas sociais. Negar isto é insistir na perpetuação de uma forma de violência que elimina da literatura tudo o que traz as marcas da diferença social e expulsa para os guetos tantas vozes criadoras $(2012$, p.8).

Muitas e novas questões surgirão nesse percurso. Um país com dimensões continentais, lugar de aporte de tantas nações africanas, possui com certeza um imenso tesouro literário a ser descoberto, entre eles o acervo de cantigas próprios da oralidade e que possuem registro em comunidades quilombolas e/ou ribeirinhas. São séculos de sombra sobre uma produção que aos poucos vai tomando seu lugar numa cena marcada pelo domínio do branco e das classes abastadas da sociedade brasileira.

É claro que num contexto escravocrata como o que viveu Maria Firmina dos Reis (1825), até o fato de ela ter publicado seus escritos com o pseudônimo "A maranhense" já representava uma resistência e uma vontade e coragem de se dizer, de ir à luz, mesmo, de desafiar o poder estabelecido, ainda que de forma temerosa e acreditando que seus escritos não tinham valor literário. São desses personagens que se precisa falar, de seus escritos, de seus estilos, de suas lutas, de sua resistência, de suas ausências.

Em torno dessa discussão uma rede de outras temáticas vão se enrizomando. Da colonialidade do poder versus saber, até às questões de base para a antropologia que constituem a Isso quando se trata do circuito oficial de publicação, editoras físicas, etc. Mas 
fica evidente também que, o contexto de acesso facilitado e rápido às informações e produção de tecnologias virtuais abriu possibilidade de divulgação de trabalhos de escritoras basta citar por exemplo o site Geledés, alguns Blogs como o das escritoras negras da Bahia e é neste contexto que Conceição Evaristo vive a sua poética de resistência e rebeldia porque "a noite não adormece nos olhos das mulheres".

\section{REFERÊNCIAS BIBLIOGRÁFICAS}

AUGE, Moema Parente. E Agora Falamos Nós": Literatura Feminina Afro-brasileira.

BARBOSA, MARCIO, "Questões sobre Literatura Negra” in Reflexões sobre a Literatura Afro-Brasileira, Quimlombhoje, São Paulo, Conselho de Participação e Desenvolvimento da Comunidade Negra do Estado de São Paulo, 1985

BERND, ZILÁ, Introdução à Literatura Negra, São Paulo, Brasiliense, 1988 , Negritude e Literatura na América Latina, Porto Alegre, Mercado Aberto, 1987, p.17.

BHABHA, Homi. O Local da Cultura. Trad. Myriam Ávila, Eliana Lourenço de Lima Reis, Gláucia Renata Gonçalves. Belo Horizonte: UFMG, 1998.

, Homi K. Disseminação: tempo, narrativa e as margens da nação moderna. Trad.

Maria L. Cyrino Valle. Belo Horizonte: UFMG/FALE - Pós-Lit, 1995.

BOSI, Alfredo. História concisa da Literatura Brasileira. São Paulo: Cultrix, 2006.

BRASIL. Senado Federal. A Abolição no Parlamento: 65 anos de luta (1823-1888), vol. 2, Brasília, 2012.

BRITO, M.C.E. de, Literatura Negra: Uma poética de nossa afro-brasilidade. Dissertação de Mestrado, PUC/RJ, 1996.

CANDIDO, Antonio. Literatura e Sociedade. Rio de Janeiro: Ouro sobre azul, 9 ed. 2006. , Antonio. Literatura de dois gumes: A Educação pela noite e outros ensaios. São Paulo: Ática, 1987, pp. 163-180.

CASTILHO, Suely D. de. A Representação do Negro na Literatura Brasileira: Novas Perspectivas. Olhar de professor, Ponta Grossa, 7(1): 103-113, 2004.

CÉSAIRE, Aimé, Discurso sobre a Negritudel Aimé Césaire; Carlos Moore (org.), Belo Horizonte: Nandyala, 2010. Coleção Vozes da Diáspora Negra, volume 3.

CHARTIER, Roger. A história cultural: entre práticas e representações. Rio de Janeiro: Bertrand Brasil, 1988. 
COLOMBO, Nayra Claudinne Guedes Menezes. Corpos negros $x$ falas brancas: as representações do negro na literatura de expressão Amazônica. 2009. 91f. Diss. UFA, Rio Branco - $\quad$ Acre, $2009 . \quad$ Disponível em: http://www.dominiopublico.gov.br/pesquisa/DetalheObraForm.do?select_action=\&co_obra=184790.

Acesso em 21 de outubro de 2016.

DALCASTAGNÈ, Regina. Um território contestado: literatura brasileira contemporânea e as novas vozes sociais. Revista Iberic@1 - Numéro2, ano?

.Literatura Brasileira Contemporânea - Um Território

Contestado . Editora Horizonte/Editora UERJ, 208 páginas.

D'ANGELO, Helô. Quem foi Maria Firmina dos Reis, considerada a primeira romancista brasileira. In: Revista CULT. Disponível em: https://revistacult.uol.com.br/home/centenario-mariafirmina-dos-reis/, 10 de novembro de 2017

DELEUZE, Gilles \& GUATTARI, Félix. Mil Platôs: capitalismo e esquizofrenia. Trad: Tradução: Aurélio Guerra Neto et alli. Rio de Janeiro: Editora 34, 1996

DUARTE, Eduardo de Assis. O negro na literatura brasileira in :Revista Navegações, Porto Alegre, v. 6, n. 2, p. 146-153, jul./dez. 2013.Ensaio.

Maria Firmina, mulher do seu tempo e do seu país. Prefácio. In: REIS, Maria Firmina dos. Úrsula; A Escrava. Florianópolis: Ed. Mulheres; Belo Horizonte: PUC Minas, 2017.

EVARISTO, Conceição Maria. Ponciá Vicêncio. Rio de Janeiro: Pallas, 2017

, Poemas da Recordação e outros movimentos. Rio de Janeiro: Malê, 2017

2008. Ver e imaginar o outro: alteridade, desigualdade, violência na literatura brasileira contemporânea. São Paulo: editora Horizonte.

$30 \mathrm{~m}$. Gravada e transcrita.

. 2017. Entrevista. Entrevistadora: Maria de Nazaré Barreto Trindade.

FANON, Franzt. Pele Preta, máscaras brancas. Centro de estudos afro-asiáticos. Rio de Janeiro, 1986

FERNANDES, Danubia de Andrade. O Gênero Negro: Apontamentos Sobre Gênero, Feminismo e Negritude. In: Estudos Feministas, Florianópolis, 24(3): 398, setembro/dezembro/2016.

FILHO, Nascimento M. Maria Firmina: fragmentos de uma vida, São Luiz,1975

FUNES, Eurípedes A. "Nasci nas matas nunca tive senhor": história e memória dos mocambos do Baixo Amazonas. (Tese de doutorado, Universidade de São Paulo, 1995).

GLISSANT, EDOUARD, Introduction à Une Poétique Du Divers, Paris,Editions, Gallimand, 1996. 
JESUS, C.M. de. Onde estaes Felicidade? - Carolina Maria de Jesus/ Dinha e Raffaella Fernandez, organizadoras. - São Paulo: Me Parió Revolução, 2014.

, Carolina Maria de. Quarto de Despejo: diário de uma favelada. São Paulo: livraria

Francisco Alves, 4. edição, 1960.

,Diário de Bitita, 1986

LOBO, LUIZA, “A Pioneira Maranhense Maria Firmina dos Reis” in Estudos Afro-Asiáticos, RJ - no $16-1989$, p.91.

, Literatura negra brasileira contemporânea, in: Estudos Afro-Asiáticos.

Cadernos Cândido Mendes, Rio de Janeiro, Nr. 14, p. 109-140, 1987.

LOPES, Nei. Dicionário literário afrobrasileiro. Rio de Janeiro. Ed. Palhas, 2007.

MARCONDES, Mariana Mazzini et al. Dossiê mulheres negras: retrato das condições de vida das mulheres negras no Brasil. Brasília: Ipea, 2013160 p.

MENDES, Algemira de Macêdo. Maria Firmina dos Reis e Amélia Beviláqua na história da literatura brasileira: representação, imagens e memórias nos séculos XIX e XX. 2006. 282 f. Tese (Doutorado em Letras), Pontifícia Universidade Católica, Rio Grande do Sul, 2006.

MIGUEL-PEREIRA, Lúcia. História da Literatura Brasileira. Prosa de ficção (1870-1920). Rio de Janeiro: Ed José Olympio, 1957.

MUSA, A.B.N., "Origens da Poesia Afro-Brasileira: Condicionamentos Lingüísticos in Estudos Afro-Asiáticos. n 19, 1990, p.56

MUZART, Zahidé Lupinacci (org.). Escritoras Brasileiras do Século XIX. Florianópolis: Mulheres; Santa Cruz do Sul: EDUNISC, 1999.

NASCIMENTO, BEATRIZ, “Kilombo” texto mimeografado, s/d

NASCIMENTO, Abdias. O genocídio do negro brasileiro. São Paulo: perspectivas, 2016 . O Quilombismo, Petrópolis, Vozes, 1980.

NEI LOPES, Incursões sobre a Pele, Rio, Artium, 1996, pp 23, 24

PROENCA FILHO, D. A trajetória do negro na literatura brasileira. Revista do patrimônio histórico e artístico nacional. Rio de Janeiro, n. 25, p. 159-177, 1997.

RIBEIRO, Darcy. O Povo Brasileiro. São Paulo: Companhia das Letras, 2006

PROENCA FILHO, D. A trajetória do negro na literatura brasileira. Revista do patrimônio histórico e artístico nacional. Rio de Janeiro, n. 25, p. 159-177, 1997.

RATTS, Alex. Eu sou Atlântica: sobre a trajetória de Beatriz Nascimento. São Paulo, 2006. 
REIS, M. Firmina dos. Úrsula: romance; A escrava: conto. Belo Horizonte: Ed. PUC- Minas, 2017.

ROCHA, José Geraldo da. e RANGEL, Patrícia Luísa Nogueira. Úrsula: a voz dos excluídos do século XIX no romance de Maria Firmina dos Reis. In: Revista Mulheres e Literatura, vol. $13,2014$.

SILVA, Régia Agostinho da, “A mente, essa ninguém pode escravizar”: Maria Firmina dos Reis e a escrita feita por mulheres no Maranhão. In: ANPUH - XXV SIMPÓSIO NACIONAL DE HISTÓRIA - Fortaleza, 2009, p.1-10

SAID, Edward W. Cultura e Imperialismo. Tradução: Denise Bottman. São Paulo: Companhia de Bolso, 2011.

SALLES, Vicente. O negro no Pará sob o regime da escravidão - (1971), Belém: IAP, Programa Raízes, 3 ed. ampliada, 2005.

SANTIAGO, Silviano. Para além da História social. Nas malhas da letra. São Paulo. Companhia das letras, 1989.

SAMPAIO, Patrícia M. (org.). O fim do silêncio - presença negra na Amazônia. Belém: Açaí / CNPq, 2011. 298 p. Disponível em: http://www.scielo.br/pdf/afro/n45/a10n45.pdf. Acesso em:

SCHWARZ, Roberto. Ao vencedor as Batatas.São Paulo: dua cidades, 1977.

SILVEIRA, Oliveira. Roteiro dos tantãs. Porto Alegre: edição do autor, 1981.

SPIVAK. G. Pode o subalterno falar? UFMG, 2010

TRINDADE, M.N.B. Carolina, A Mulher pelo avesso: uma poética do desassossego", publicado nos anais do V CIELLA, 2016

Sites:

Estudos Feministas (Rio de Janeiro), v. 7, n. 1. 2, 1999

http://homoliteratus.com/10-escritores-brasileiros-negros/

https://www.ufmg.br/online/arquivos/022092.shtml Portal da ufmg de literatura 